\title{
Statistical Methods of Images Analysis as an Essential Tool in the Assessment Process of Computer Methods Intended for Numerical Simulations of Cavitating Flows
}

\author{
Agnieszka Niedźwiedzka*1, Seweryn Lipiński² \\ ${ }^{1}$ Department of Mechanics and Basics of Machine Design, Faculty of Technical Sciences, \\ University of Warmia and Mazury in Olsztyn, Poland \\ 2Department of Electric and Power Engineering, Electronics and Automatics, Faculty of \\ Technical Sciences, University of Warmia and Mazury in Olsztyn, Poland \\ *corresponding author: agnieszka.niedzwiedzka@uwm.edu.pl
}

\begin{abstract}
Cavitation, because of its negative effects, like e.g. erosion, noise or vibration, is usually an undesirable phenomenon. However, in devices where spraying and atomization are expected, cavitation is required. This group of devices includes e.g. diesel injectors. Appearance of vapour bubbles results in increase of the maximum flow velocity. It is possible for the following reasons. Firstly, bubbles start to form in the throat, so its diameter reduces. Secondly, appearance of vapour bubbles along the wall results in a slip boundary condition. Moreover, cavitation has a positive influence on a spray cone angle. However, regardless of the place of occurrence, research on cavitation bases primarily on numerical simulations. The area of numerical methods intended for cavitating flows includes many solutions which differ not only in the basic assumptions, i.e. considering flow either as a multiphase mixture with the average density or just as two independent liquids, fluid and vapour, with a distinct boundary between them, but also in many methods applied in particular approaches. Currently, to choose the best way of the prediction of cavitation phenomenon for the undertaken issue, many aspects should be considered. The most important factor is the assessment level between the results of numerical simulation and experimental data. Secondary are computing time, requirements for the hardware, price of software and additional costs connected with the selected software. The final decision about the chosen way of the cavitation prediction results from all the above-considered elements. The main aim of the work is to present the methods of image analysis, which can be very helpful in this process. The main advantage of these methods is the quantitative answer about the correlation degree between analysed images. It eliminates subjective decisions based solely on a raw imaging material. The image material used in the work was obtained via numerical simulations performed in ANSYS Fluent. Presented methodology bases on their statistical analysis that considers the shape and intensity of cavitating area, as well as on basic methods of image processing and analysis. The conclusion is that the obtained results demonstrate the usefulness of the proposed methods in the aspect of a reliable comparison of images obtained in the numerical studies of the cavitation phenomenon.
\end{abstract}

\section{Keywords}

Cavitating flow, numerical simulations, assessment process, statistical analysis, image analysis.

\section{Introduction}

Cavitation is one of the most investigated topics in the area of fluid flow research. This phenomenon itself consists in growth of vapour bubbles in a fluid under the influence of drop in pressure below the saturated liquid pressure and it is usually considered as an undesirable phenomenon, because of its negative effects, which are inter alia erosion, noise, vibration and loss of efficiency [1], [7], [10]. However, cavitation can be useful; moreover, there are situations where it can be desired. Cavitation accompanies and determines such phenomena as spraying and atomization that are required in many devices. The example of such device is diesel injector [10], [1]. Through the appearance of vapour bubbles, the maximum flow velocity increases; it is possible for the following two reasons. Firstly, bubbles start to form in the throat, so its diameter reduces. Secondly, appearance of vapour bubbles along the wall results in a slip boundary condition. Cavitation has also a positive influence on a spray cone angle [19]. Collapse of the cavitation bubbles enhances fuel atomization. The collapse results in decrease of droplets size what is beneficial for vaporization. A faster vaporization helps to mix fuel and air and to reduce ignition delay [24]. The biggest difficulty for experimental and numerical investigations of engine diesel injectors are small dimensions (the inner diameter is about $200 \mu \mathrm{m}$ ) and a very fast flow velocity, even about $500 \mathrm{~m} / \mathrm{s}$. For that reasons, to extract data for validation of the results of numerical simulations special tools should be applied [20]. 
Regardless of the place of occurrence, research on cavitation bases primarily on numerical simulations [13], [21]. The area of numerical methods intended for cavitating flows includes many solutions. Primarily they differ in the basic assumptions, i.e. considering flow as a multiphase mixture either with the average density or just as two independent liquids, fluid and vapour, with a distinct boundary between them. Other differences stems from the use of many methods applied in particular approaches. All methods base on the governing equations of mass, momentum and energy [23]:

$$
\begin{aligned}
& \frac{\partial \rho}{\partial t}+\operatorname{div}(\rho \vec{u})=0 \\
& \frac{\partial}{\partial t}(\rho \vec{u})+\operatorname{div}(\rho \vec{u} \otimes \vec{u})=\operatorname{div}\left(-p \vec{I}+\vec{\tau}^{m}+\vec{\tau}^{R}\right)+\rho s_{b} \\
& \frac{\partial}{\partial t}(\rho e)+\operatorname{div}(\rho e \vec{u}+\rho \vec{u})=\operatorname{div}\left[\left(\vec{\tau}^{m}+\vec{\tau}^{R}\right) \vec{u}+\vec{q}^{m}+\vec{q}^{R}\right]+\rho s_{e}
\end{aligned}
$$

This set of equations can be solved independent or jointly for each of the phases, which are liquid and vapour. The first solution (based on independent solutions), because of longer computing time and bigger system requirements, is rarely preferred. In the second, more economical option, two ways are considered: solving an additional transport or a barotropic equation. The additional transport equation describes conditions of change of physical state from liquid to vapour and vice versa and it is expressed in a form of source terms. The most solutions of source terms base on the Rayleigh equation [17]:

$$
R \frac{d^{2} R}{d t^{2}}+\frac{3}{2}\left(\frac{d R}{d t}\right)^{2}=\frac{p_{s a t}-p}{\rho_{l}}
$$

In order to choose the best way of the prediction of cavitation phenomenon for the undertaken issue many aspects should be considered. The most important factor is the assessment level between the results of numerical simulation and experimental data. Secondary are computing time, requirements for the hardware, price of software and additional costs connected with the selected software. The final decision on the chosen way of the cavitation prediction should be a result taking into account all the above-mentioned elements. The raw image material, showing contours of vapour volume fraction, is a vexed basis for the key question concerning the assessment level of the results. The qualitative answer is the best possible solution. It eliminates a subjective view and gives unequivocal and irrefutable proofs of the made choice. The literature concerning the statistical methods of image analysis aiming to define correlation coefficients is very poor and the proposed methods have not gained popularity in the research area of cavitating flows. The image analysis was used e.g. for calculating the Volumetric Index necessary for determination of the fouling degree of the injectors [25] or to determine the mean error between vapour penetration measurements and simulations [4]. The statistical methods dominate either in validation of quantitative data, such as mass flow rate or temperature [16]. Many reasons can be listed for this state of affair, beginning from a small interest in such comparisons methods and ending in lack of any strictly specified requirements in evaluation of the achieved numerical results. Despite the fact that in the area of numerical simulations of the flow in engine diesel injectors a progress is visible each year, validation of the achieved results stays usually at the same level and the traditional raw image analyses still dominate [2], [3], [5], [8], [18]. Paying more attention to the statistical image analysis could be a real and desired support for the rapidly growing area of numerical calculations, not only for devices like diesel injectors. This work is an attempt to popularize the statistical methods of image comparisons as an excellent, unequivocal and simple solution that help to make the best choice without any doubts about the influence of subjective perspective.

\section{Aim}

The main aim of the work is to present the methods of statistical image analysis of cavitating area. Using basic methods of image processing two correlation coefficients are proposed. The first correlation coefficient bases on the intensity of the cavitation cloud while the second on the changes in the shape of the cavitation cloud. Both proposed coefficients can be helpful in the process of the assessment of results obtained in numerical simulations. The original achievement are also the results of the numerical simulations of cavitating flow in form of the contours of vapour volume fraction that are used in the further statistical image analysis.

It should be emphasized, that proposed coefficients can successfully be used for the purpose of comparing results of simulations with experiment as well; as it is described in the "Conclusions" section. 


\section{Material and methods}

The analysed axisymmetric and two-dimensional geometry is an orifice which dimensions are shown in Figure 1. The total length of the orifice is equal to $48 \mathrm{~mm}$, the length of the inlet part is equal to $16 \mathrm{~mm}$, the inlet diameter is equal to $23.04 \mathrm{~mm}$ and the outlet diameter equals to $8 \mathrm{~mm}$. The inspiration for the geometry is the "Cavitation modeling" tutorial [29]. In accordance with the guide, the inlet pressure is equal to 5 bar and the outlet pressure to 9.5 bar. The numerical calculations are performed for steady state.

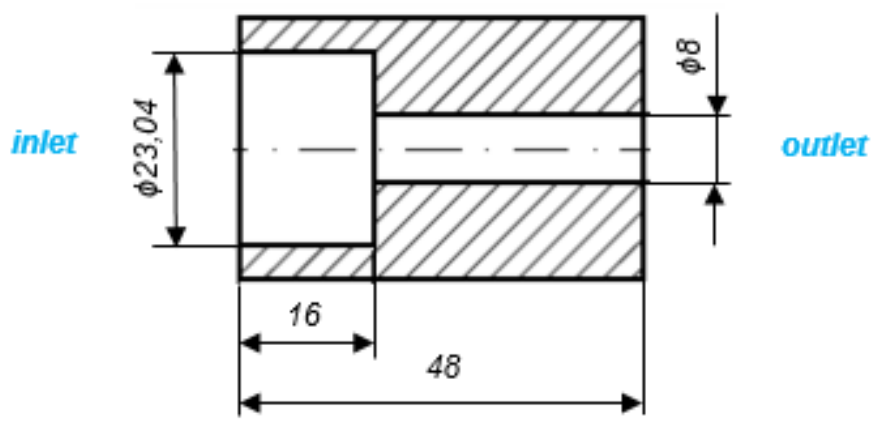

Figure 1. Dimensions of the analysed orifice.

The material for the analysis of the validity of the application of statistical methods of image processing in the assessment of the compliance degree of achieved results are the contours of the vapour volume fraction achieved in numerical simulations of cavitating flow in the orifice. Seven homogeneous cavitation models are considered: Iben [9], Kunz et al. [11], Merkle et al. (1998) [12], Merkle et al. (2006) [13], Schnerr and Sauer [21], Singhal et al. [22] and Zwart et al. [26]. The source terms of the chosen models are presented in Table 1. The numerical simulation are performed using Fluent software, a part of the Ansys 14.5 package. All the models are implemented using UDFs (User Defined Functions) with the built-in macro Define Cavitation Rate [27]. Verification of the used UDFs is presented in the work by Niedźwiedzka et al [15].

Table 1. Source terms of the analysed cavitation models.

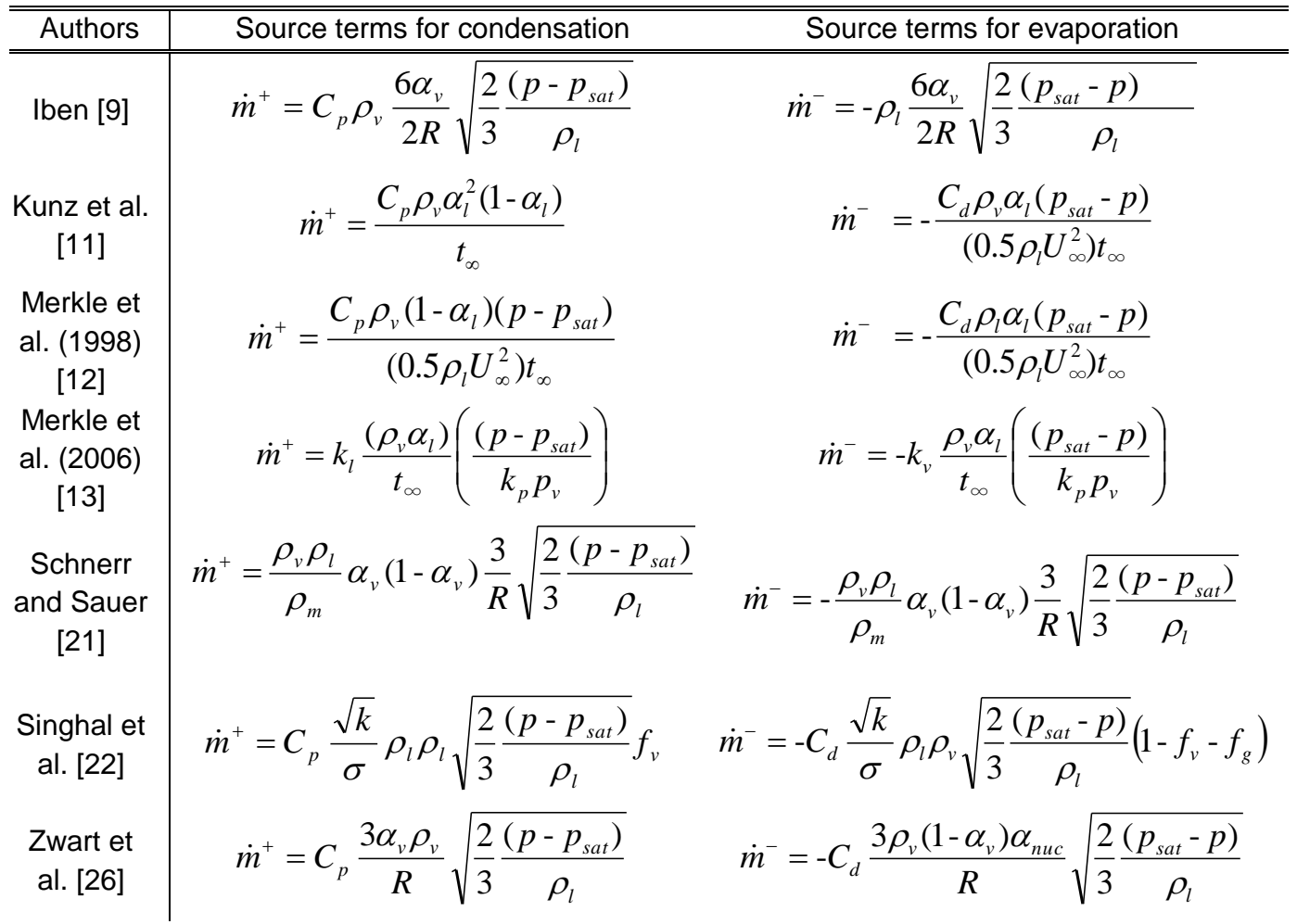


The images obtained in the simulations are shown in Figure 2. It can be seen that the contours of the vapour volume fraction are very similar for the each considered solution. The length of the cavitating area is close to the outlet of the orifice or finishes at the outlet edge. The intensity of the cavitating cloud is also variable for each of the analysed variant what is the most visible at the edges of the part with the smaller diameter. The biggest intensity of cavitation is located at place where the diameter rapidly changes. For each of the contours the same scale was used where the maximum value of the vapour volume fraction is 0.99 .

Images shown in Figure 2 were used to achieve the main aim of the work, which was to present the methods of statistical image analysis, which can help in the process of the assessment of results obtained in numerical simulations of cavitation phenomenon.

a)

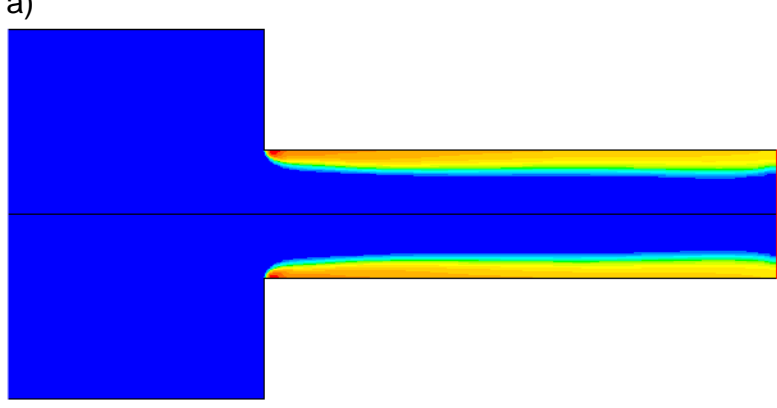

c)

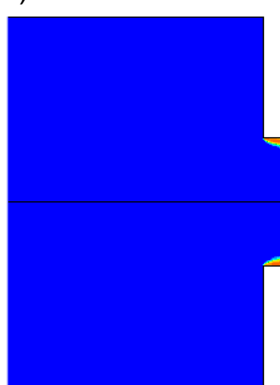

e)

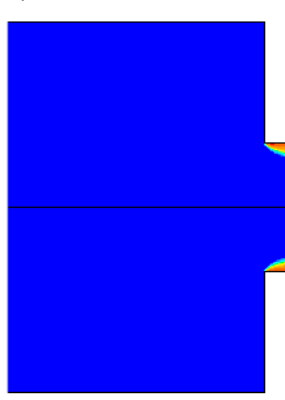

g)

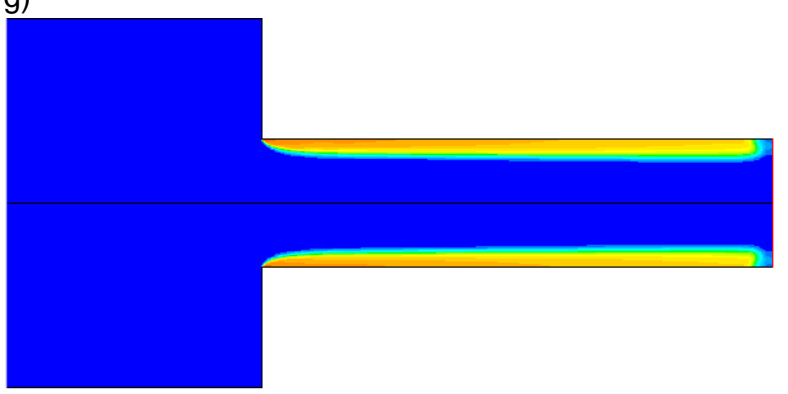

b)

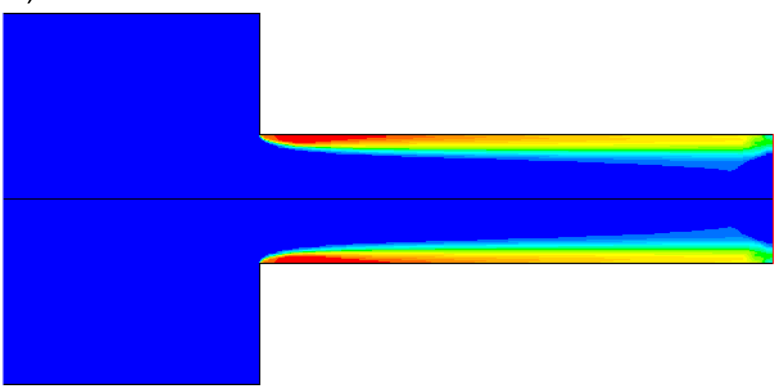

d)

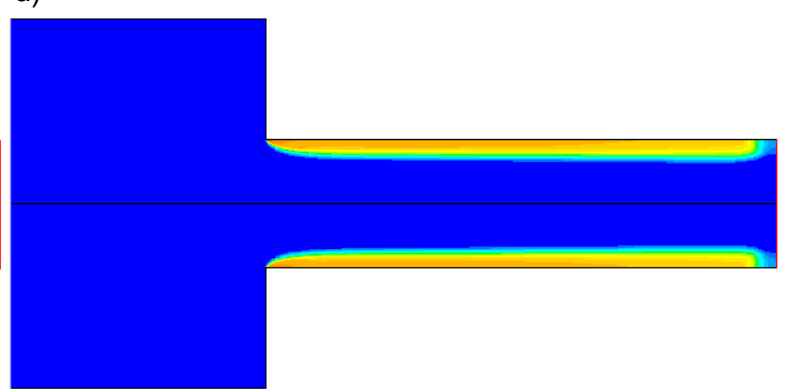

f)
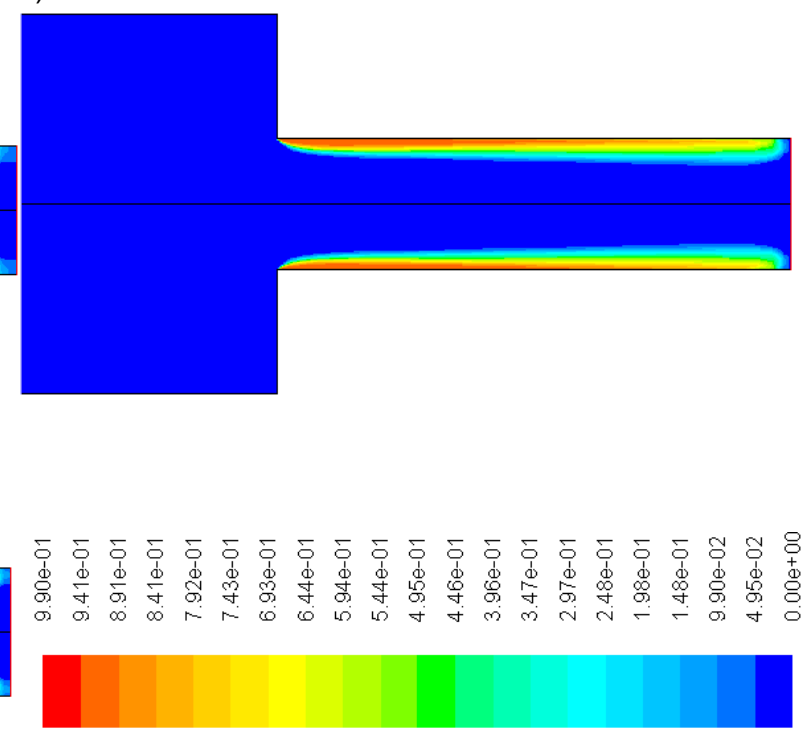

Figure 2. Images of cavitating flow obtained via numerical simulations in the described orifice: Iben model (a), Kunz et al. model (b), Merkle et al. model 1998 (c), Merkle et al. model 2006 (d), Schnerr and Sauer model (e), Singhal et al. model (f) and Zwart et al. model (g). 
Presented methodology bases on their statistical analysis that considers the shape and intensity of cavitating area, as well as on basic methods of image processing and analysis. In order to evaluate obtained results in an objective manner, we propose to introduce two correlation coefficients. Each of them has a different purpose. The first coefficient ( $r_{1}$ - intensity correlation coefficient) bases on the intensity of cavitation; it is a 2-D equivalent for a Pearson product-moment correlation coefficient and is defined as follows:

$$
r_{I}=\frac{\sum_{x=1}^{X} \sum_{y=1}^{Y}\left(A_{x y}-\bar{A}\right)\left(B_{x y}-\bar{B}\right)}{\sqrt{\left(\sum_{x=1}^{X} \sum_{y=1}^{Y}\left(A_{x y}-\bar{A}\right)^{2}\right)\left(\sum_{x=1}^{X} \sum_{y=1}^{Y}\left(B_{x y}-\bar{B}\right)^{2}\right)}} .
$$

This coefficient gives information on how correlated are intensities of cavitation in images being compared. Typical values of this coefficients are in range from -1 to 1 , where 1 is the total positive correlation, 0 is no correlation, and -1 is total negative correlation.

The second correlation coefficient ( $r_{s}$ - shape correlation coefficient) is supposed to show similarity in changes of the shape of cavitation cloud. It is calculated using formula (5) as well, but in that case, the operation is performed on $I_{D}$ images, which are created in order to show changes in cloud intensities (not intensities per se). Individual pixels (with $x$ and $y$ coordinates) of $I_{D}$ images are obtained as:

$$
I_{D_{x y}}=I_{(x+1)(y+1)}-I_{x y}, x=1,2, \ldots, X-1, y=1,2, \ldots, Y-1 .
$$

Obtained values of this coefficient should be interpreted just as values of the rıcoefficient.

\section{Results and discussion}

Table 2 shows obtained values of the $r$ c coefficient for each combination (pair) of considered models.

\begin{tabular}{|c|c|c|c|c|c|c|c|}
\hline & Iben & Kunz et al. & $\begin{array}{c}\text { Merkle et al. } \\
(1998)\end{array}$ & $\begin{array}{c}\text { Merkle et al. } \\
(2006)\end{array}$ & $\begin{array}{c}\text { Schnerr and } \\
\text { Sauer }\end{array}$ & $\begin{array}{c}\text { Singhal et } \\
\text { al. }\end{array}$ & $\begin{array}{c}\text { Zwart et } \\
\text { al. }\end{array}$ \\
\hline Iben & 1 & 0.93 & 0.92 & 0.92 & 0.92 & 0.92 & 0.93 \\
\hline Kunz et al. & 0.93 & 1 & 0.96 & 0.93 & 0.94 & 0.95 & 0.94 \\
\hline $\begin{array}{c}\text { Merkle et al. } \\
\text { (1998) }\end{array}$ & 0.92 & 0.96 & 1 & 0.93 & 0.94 & 0.97 & 0.94 \\
\hline $\begin{array}{c}\text { Merkle et al. } \\
\text { (2006) }\end{array}$ & 0.92 & 0.93 & 0.93 & 1 & 0.99 & 0.96 & 0.99 \\
\hline Schnerr and Sauer & 0.92 & 0.94 & 0.94 & 0.99 & 1 & 0.97 & 0.99 \\
\hline Singhal et al. & 0.92 & 0.95 & 0.97 & 0.96 & 0.97 & 1 & 0.97 \\
\hline Zwart et al. & 0.93 & 0.94 & 0.94 & 0.99 & 0.99 & 0.97 & 1 \\
\hline
\end{tabular}

Table 2. Values of the $r_{i}$ correlation coefficients for each combination of considered models.

Table 3 shows obtained values of the $r_{s}$ coefficient for each combination (pair) of considered models.

Table 3. Values of the $r_{S}$ correlation coefficients for each combination of considered models.

\begin{tabular}{c|cccccccc}
\hline \hline & Iben & Kunz et al. & $\begin{array}{c}\text { Merkle et } \\
\text { al. (1998) }\end{array}$ & $\begin{array}{c}\text { Merkle et al. } \\
(2006)\end{array}$ & $\begin{array}{c}\text { Schnerr and } \\
\text { Sauer }\end{array}$ & $\begin{array}{c}\text { Singhal et } \\
\text { al. }\end{array}$ & $\begin{array}{c}\text { Zwart et } \\
\text { al. }\end{array}$ \\
\hline \hline Iben & 1 & 0.21 & 0.17 & 0.15 & 0.16 & 0.15 & 0.16 \\
Kunz et al. & 0.21 & 1 & 0.39 & 0.44 & 0.42 & 0.35 & 0.43 \\
$\begin{array}{c}\text { Merkle et al. } \\
\text { (1998) }\end{array}$ & 0.17 & 0.39 & 1 & 0.29 & 0.34 & 0.47 & 0.34 \\
$\begin{array}{c}\text { Merkle et al. } \\
\text { (2006) }\end{array}$ & 0.15 & 0.44 & 0.29 & 1 & 0.77 & 0.38 & 0.85 \\
$\begin{array}{c}\text { Schnerr and Sauer } \\
\text { Singhal et al. }\end{array}$ & 0.16 & 0.42 & 0.34 & 0.77 & 1 & 0.45 & 0.85 \\
Zwart et al. & 0.15 & 0.35 & 0.47 & 0.38 & 0.45 & 1 & 0.43 \\
\end{tabular}


Figures 3 and 4 shows the values from the Tables 2 and 3 in a graphical form.

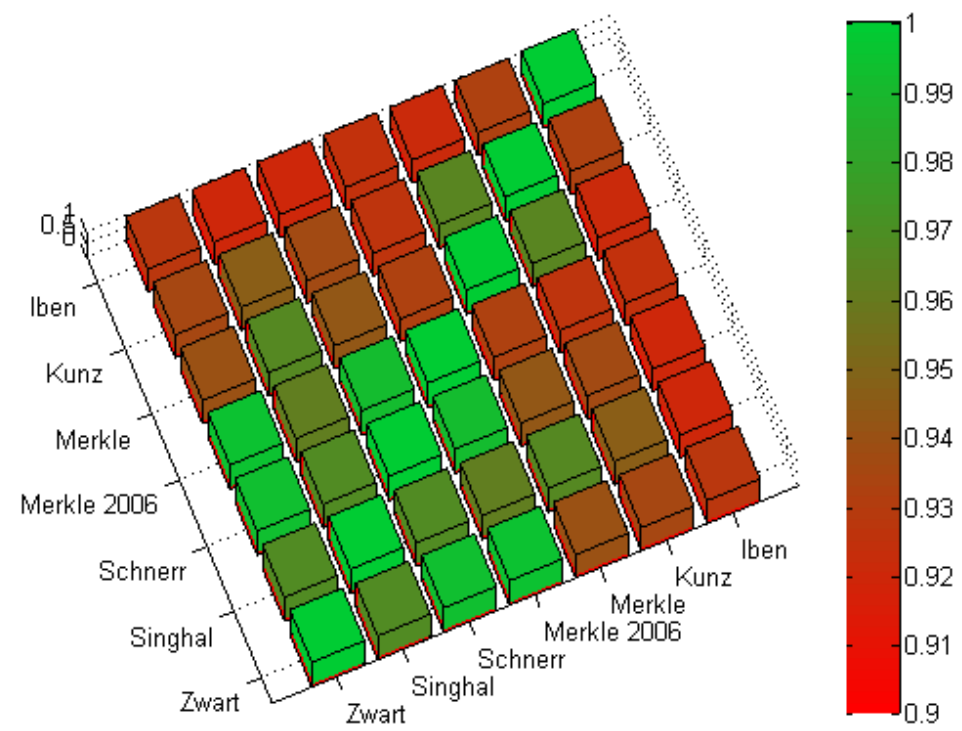

Figure 3. Values of the $r_{i}$ correlation coefficients for each combination of considered models.

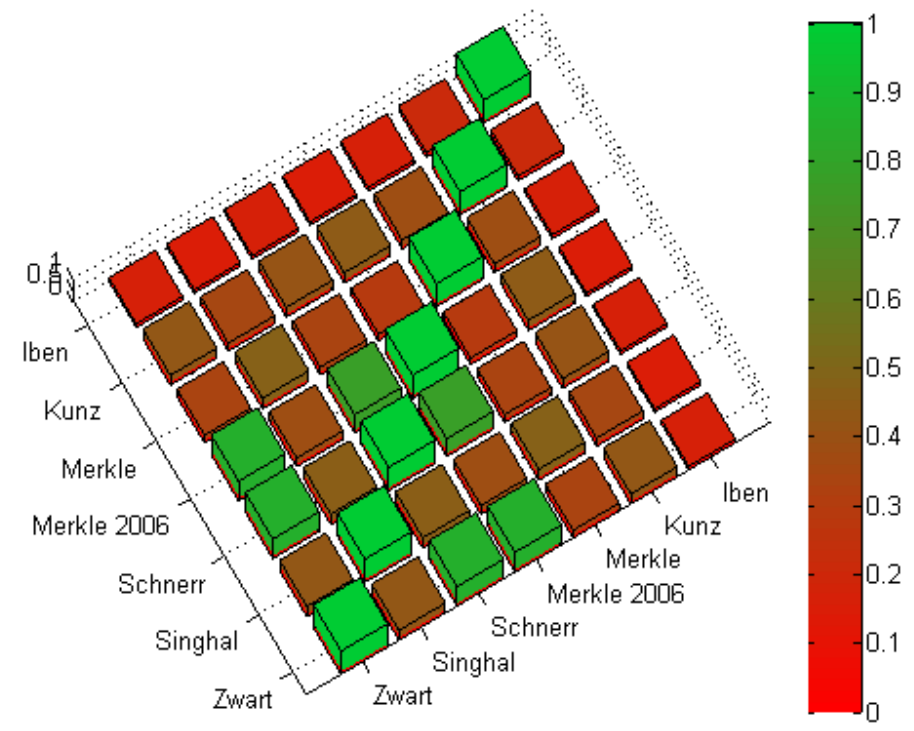

Figure 4. Values of the $r_{s}$ correlation coefficients for each combination of considered models.

The analysis of Table 2 and Figure 3 shows that considering the intensity of the cavitation cloud the best correlated models are three pairs: the Merkle et al. model (2006) and the Schnerr and Sauer model, the Merkle et al. model (2006) and the Zwart et al. model and the Schnerr and Sauer model and the Zwart et al. model. Ale the mentioned pairs achieved an excellent value of correlation, namely $99 \%$. The next group of the best correlated models constitutes of six pairs: the Singhal et al. model and the Merkle et al. model (1998), the Singhal et al. model and the Schnerr and Sauer model, the Singhal et al. model and the Zwart et al. model, the Singhal et al. model and the Merkle et al. model (2006), the Merkle et al. model (1998) and the Kunz et al. model and the Singhal et al. model and the Kunz et al. model. The values of the first correlation coefficients are as follows: $97 \%, 97 \%, 97 \%, 96 \%, 96 \%$ and $95 \%$. The last twelve pairs, i.e. showing the worst values of the used correlation coefficient, correlate with others on the level of $94 \%, 93 \%$ and $92 \%$. The worst correlated model is the lben model. It achieves the correlation value of $92 \%$ with four models: the Merkle et al. model (1998), the Merkle et al. model (1998), the Schnerr and Sauer model and the Singhal et al. model. 
The analysis of Table 3 and Figure 4 shows significantly lower values of the second correlation coefficient than these from Table 2. Two pairs are best-correlated: the Merkle et al. model (2006) and the Zwart al. model and the Merkle et al. model (2006) and the Schnerr and Sauer model. The values of the correlation coefficient are $85 \%$ and $77 \%$, respectively. The next well correlated group has six pairs: the Merkle et al. model and the Singhal et al. model, the Schnerr and Sauer model and the Singhal et al. model, the Merkle et al. model (2006) and the Kunz et al. model, the Zwart et al. model and the Kunz et al. model, the Zwart et al. model and the Singhal et al. model, the Schnerr and Sauer model and the Kunz et al. model. The values of the first correlation coefficients are as follows: $47 \%$, $45 \%, 44 \%, 43 \%, 43 \%$ and $42 \%$. The worst correlated is once again the lben model. The values of the correlation coefficient are even 15\% for the Merkle et al. model (2006) and the Singhal et al. model.

From the both analysis results unambiguously that the best-correlated pair is the Merkle et al. model and the Zwart et al. model. The second correlation coefficient turned out very useful even though it initially seemed to be superfluous. Thanks to this coefficient, we managed to extract the best-correlated pair from the five pairs with the same correlation coefficient considering the intensity of the cavitation cloud.

\section{Conclusions}

One of the major challenges during analyses of images obtained in numerical analysis of cavitating flows is their objective comparison. In other words, the goal here is not to just state that different models produce different results, but to get an objective measure of the stated difference. Our work proposes the solution for that problem.

The presented methods allow obtaining the quantitative answer about the correlation degree between analysed images in terms of shape of cavitation cloud and intensity of cavitation. The main advantage here is the elimination of subjective decisions based solely on a raw imaging material.

Obtained results demonstrate the usefulness of the proposed methods as they allow comparing images obtained in the numerical studies of the cavitation phenomenon in a reliable and objective way. One of the conditions to make such a claim are the differences between obtained correlation coefficients of shape and intensity.

It should be noted that proposed coefficients can successfully be as well used for the purpose of comparing results of simulations with experiment. For that purpose, it is only necessary to ensure the coherence of the geometrical dimensions of the image obtained in the experiment with the dimensions of the image obtained in the numerical simulations, and to normalize the intensity of the images being compared. Depending on the experimental method, it may also be necessary to properly pre-process the image. The volume and scope of this work does not allow for such comparison; it will be done in our future work.

\section{Nomenclature}

\begin{tabular}{|c|c|}
\hline$A, B$ & compared images \\
\hline$C_{d}$ & evaporation model constant [-] \\
\hline$C_{p}$ & condensation model constant $[-]$ \\
\hline$e$ & energy [J] \\
\hline$f_{g}$ & mass fraction of noncondensible gases [-] \\
\hline$f_{y}$ & vapour mass fraction [-] \\
\hline$I_{D}$ & differential image \\
\hline$k$ & turbulence kinetic energy $\left[\mathrm{m}^{2} / \mathrm{s}^{2}\right]$ \\
\hline$k_{p}$ & scaling constant $[-]$ \\
\hline$k_{y}$ & scaling constant [-] \\
\hline$\dot{m}^{+}$ & mass source for condensation $\left[\mathrm{kg} /\left(\mathrm{m}^{3} \cdot \mathrm{s}\right)\right]$ \\
\hline $\begin{array}{l}\dot{m}^{-} \\
p\end{array}$ & $\begin{array}{l}\text { mass source for evaporation }\left[\mathrm{kg} /\left(\mathrm{m}^{3} \cdot \mathrm{s}\right)\right] \\
\text { local fluid pressure }[\mathrm{Pa}]\end{array}$ \\
\hline$p_{\text {sat }}$ & saturated vapour pressure $[\mathrm{Pa}]$ \\
\hline$p \vec{I}$ & spherical stress tensor $[\mathrm{Pa}]$ \\
\hline$\vec{q}^{m}$ & molecular heat flux $\left[\mathrm{kg} / \mathrm{s}^{3}\right]$ \\
\hline$\vec{q}^{R}$ & turbulent heat flux $\left[\mathrm{kg} / \mathrm{s}^{3}\right]$ \\
\hline$R$ & bubble radius [m] \\
\hline$r_{I}$ & intensity correlation coefficient [-] \\
\hline
\end{tabular}




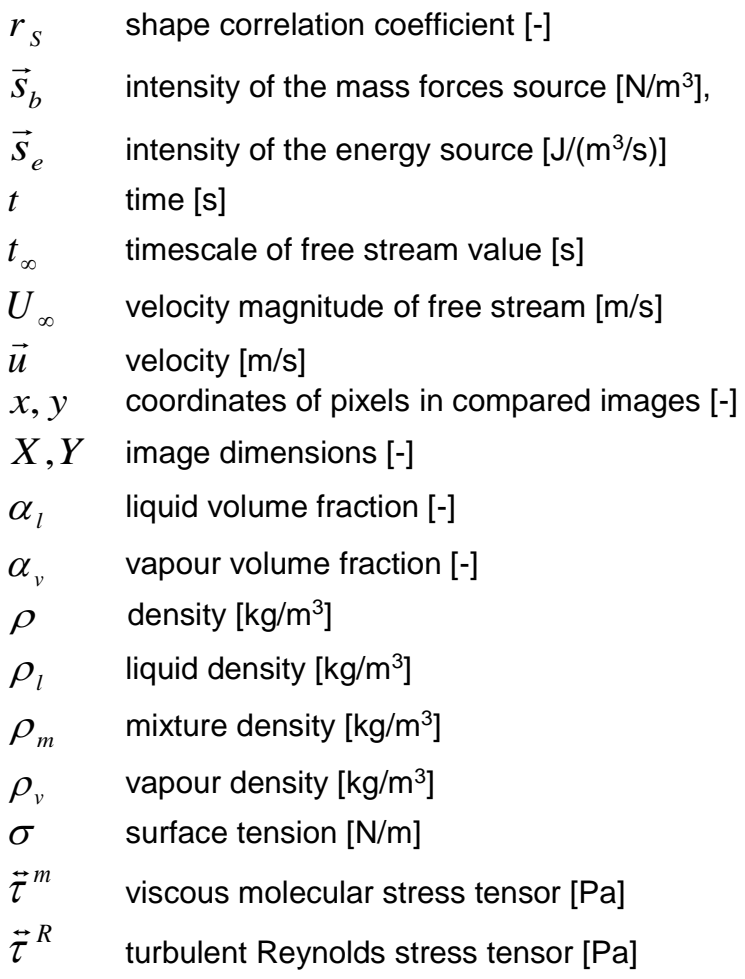

\section{References}

[1] Andriotis, A., Gavaises, M., Arcoumanis, C., 2008, Journal of Fluid Mechanics, 610, pp. 195-215.

[2] Bunnell, R. A., Heister, S. D., Yen, C., Collicott, S. H., 1999, Atomization and Sprays, 9 (5), pp. 445-465.

[3] Chen, Y., Heister, S. D., 1996, Atomization and Sprays, 6 (6).

[4] Fitzgerald, R. P., Gehrke, C., Svensson, K., Martin, G., 2017, SAE Technical Paper, No. 2017-01-0826).

[5] Giannadakis, E., Gavaises, M., Arcoumanis, C., 2008, Journal of Fluid Mechanics, 616, pp. 153-193.

[6] Gohil, P. P., Saini, R. P., 2014, Renewable and Sustainable Energy Reviews, 33, pp. 280-289.

[7] Gupta, M. K., Sharma, D. S., Lakhera, V. J., 2016, Applied Mechanics Reviews, 68 (3), p. 030801.

[8] Habchi, C., Dumont, N., Simonin, O., 2008, Atomization and Sprays 18 (2).

[9] Iben, U., 2002, Systems Analysis Modeling Simulations, 42, pp. 1283-1307.

[10] Kim, K. H., Chahine, G., Franc, J. P., Karimi, A., 2014, "Advanced experimental and numerical techniques for cavitation erosion prediction".

[11] Kunz, R. F., Boger, D. A., Stinebring, D. R., Chyczewski, T. S., Lindau, J. W., Gibeling, H. J., Venkateswaran, S., Govindan, T. R., 2000, Computers and Fluids, 29 (8), pp. 849-875.

[12] Merkle, C. L., Feng, J., Buelow, P. E. O., April 7. - 10. 1998, 3rd International Symposium on Cavitation.

[13] Merkle, C. L., Li, D., Venkateswaran, S., Jul. 9. - 12. 2006, 42nd AIAA/ASME/SAE/ASEE Joint Propulsion Conference.

[14] Mirshahi, M., Yan, Y., Nouri, J. M., 2015, Journal of Physics: Conference Series, 656 (1), p. 012093.

[15] Niedźwiedzka, A., Lipiński, S., Kornet, S., 2017, Journal of Hydroinformatics, DOI: 10.2166/hydro.2017.004.

[16] Payri, R., Salvador, F. J., Carreres, M., De la Morena, J., 2016, Energy Conversion and Management, 114, pp. 376-391.

[17] Rayleigh, L., 1917, Philosophical Magazine, 34, pp. 94-98.

[18] Salemi, R., Koukouvinis, P., Strotos, G., McDavid, R., Wang, L., Li, J., Marengo, M., Gavaises, M., 2015, Journal of Physics: Conference Series, 656 (1), p. 012083.

[19] Salvador, F. J., Romero, J. V., Roselló, M. D., Martínez-López, J., 2010, Mathematical and Computer Modelling, 52 (7), pp. 1123-1132.

[20] Schmidt, D. P., Rutland, C. J., Corradini, M. L., 1999, Atomization and sprays, 9 (3), pp. 255-276.

[21] Schnerr, G. H., Sauer, J., May 27. - Jun. 1. 2001, 4th International Conference on Multiphase Flow.

[22] Singhal, A. K., Athavale, M. M., Li, H., Jiang Y., 2002, Journal of Fluids Engineering, 124, pp. 617-624.

[23] Sobieski, W., 2011, Technical Sciences, 14, 299-313.

[24] Whitelaw, J. H., Payri, F., Desantes, J. M., 2002. "Thermo-and Fluid-dynamic Processes in Diesel Engines: Selected papers from the THIESEL 2000 conference held in Valencia, Spain, September 13-15, 2000".

[25] Zampilli, M., Bartocci, P., Bidini, G., Fantozzi, F., 2016, Energy Procedia, 101, pp. 693-700.

[26] Zwart, P. J., Gerber, G., Belamri, T., May 30. - Jun. 4. 2004, 5th International Conference on Multiphase Flow.

[27] ANSYS Fluent, http://www.ansys.com/Products/Fluids/ANSYS-Fluent ([cit. 2017-02-08])

[28] Ansys Fluent Tutorial Guide, http://www.ansys.fem.ir/ansys fluent tutorial.pdf ([cit. 2017-02-08]). 